\title{
Everlasting Classics: The New Model of the Expression of Traditional Culture in the New Era
}

\author{
DING Aiwei \\ College of Media and Communication, Zaozhuang University \\ Zaozhuang, Shandong, 277160
}

\begin{abstract}
Today, the cultural variety show market is faced with development impediment such as homogeneity and fatigue, but Everlasting Classics is still in its infancy and has realized phenomenal communication. Combining with the characteristics of the new era context, this paper makes a systematic text analysis on The Everlasting Classics, and explores the innovative expression of poems and even traditional culture in the new era as follows: The multidimensional innovative program format, the content expression of the times, and the shared transmission mechanism. We hope to provide new ideas and experiences for the development of subsequent cultural variety shows.
\end{abstract}

Keywords-Cultural variety shows; Everlasting Classics; Traditional culture; Era innovation

\section{INTRODUCTION}

On June 15, 2018, Everlasting Classics, jointly created by CCTV Comprehensive Channel and CCTV Creative Media, won the Magnolia Award for Best Season Television Program Award in the 24th Shanghai TV Festival. As China's first largescale poetry + music cultural program, The Everlasting Classics combines literariness and musicality ingeniously. According to the characteristics of the new era context and keeping pace with the times, it has made many innovations and practices in three aspects: innovating the form of TV programs, innovating the content expression of programs, and creating the core mechanism of programs. Phenomenal communication is realized and can be regarded as an example of innovation and expression in the new era of traditional culture.

\section{MULTI-DIMENSIONAL INNOVATIVE PROGRAMMING}

\section{A. Ingenuity of Innovative Mode}

The main creative team has changed the traditional cultural communication mode, which used to be dominated by poetry competition and letter reading. Adopting the cross-border Concerto of "music + poetry" and "poem with song" to return to the origin of poetry, the new form of TV expression of traditional cultural programs has been created.

In people's conventional impression, the interpretation of ancient poems and lyrics generally pay attention to the ancient style and charm, and the choice of musical instruments are mainly Guzheng, Guqin and Pipa. However, in The Everlasting Classics, the interpretation of ancient poetry pays more attention to the combination with the current era. On the basis of taking into account the meaning of poetry, the classical singer deduces traditional poetry with modern singing methods, and adds new "partners" such as robot, rap, hip-pop, rock, bass, guitar, piano, and so on. It created the current popular classics, so that the audience can fully appreciate the rhyme of poetry, music, emotional truth, high spirit, and produced a good dissemination effect.

\section{B. A Diverse Lineup of Distinguished Guests}

The classical singers of are diversified as a whole. They include famous artists, famous musicians, young singers, film and television stars, Olympic champions, representatives of folk songs, teachers, and many ordinary people who love life, such as Hubei folk song peasants' team, young people in Wumeng Mountain drawing from poetry, the anti-cancer peasant woman Bai Ruyun and so on. The age span is also very large, up to the 88-year-old pianist teacher Wu Yili, down to a four-year-old boy Wang Hengyi who can recite a thousand poems. This difference in occupation and ages exactly explains the purpose of the show: calling on the whole people to sing classics, completing the Chinese excellent traditional culture from generation to generation, inheriting forever. The appreciation troupe, composed of cultural scholars, musicians and singers, jointly commented on literature, emotion, music, the origin of creation and the stories behind it. It deconstructed and excavated the mainstream value expression of poetry and music in a multidimensional way, so that the audience could not only know the words but also get their profound meaning and awaken the sense of mission and responsibility of inheritance in the cultural heyday.

\section{Internationalized Musical Expression}

Everlasting Classics is praised as a voice card to promote Chinese traditional culture. This promotion is not only confined to China, but also an attempt to extend abroad. The representative is "Climbing the Stork Tower" sung by Kokang Duplessy Mad Horse Band, which brings together artists from China, France, India and Mongolia. It also integrates the classical instruments of Erhu, classical guitar, Salange and horse-headed violin. It is accompanied by a foreign version translated by $\mathrm{Mr}$. Xu Yuanchong and sung by Vienna Mozart Children's Choir in the languages of China, Britain and German, which crosses the ancient and modern boundaries and realizes the internationalization of Chinese traditional culture. Technological innovation promotes the innovation of program forms. Singing classics, opening and sharing with heart, and equipping the audience with wearable heart-shaped devices in 
The Everlasting Classics, the audience and guests can express their love for the heart-beating classical singing by lighting up the red heart. The portrait is instantly transmitted to the big screen of broadcasting, and the gathered power blossoms out in real time to honor the classics. This intelligent on-site interaction adds to the ceremonial and belief power of the program. At the same time, each song is set with a tweet shake to encourage audiences inside and outside the stadium to share the resonance effect in a way that makes the classic popular again. This cross screen interaction bundles viewers and programs, generating and generalizing shared values.

\section{THE CONTENT EXPRESSION WHICH KEEPS PACE WITH THE TIMES}

In his speech at the Forum on literary and artistic work, Xi Jinping stressed that "only when literature and art are rooted in real life and keep up with the trend of the times can they develop and prosper, and only when they conform to the wishes of the people and reflect their concerns can they be full of vitality." "Everlasting Classics" focuses on the expression of traditional culture in the new era, excavating the Chinese spirit contained in classical poetry, accurately positioning the current mainstream values, vigorously promoting content innovation in the context of the new era, to achieve a perfect cross-border integration of poetry and music.

\section{A. Selection of Topic Resources is Keeping Pace with the Times}

Fifty-seven classical songs were sung in the Ten Issues of The Classic Songs. By sorting out the songs, the author finds that the topics of the program are mainly concentrated in the following aspects:

Fifteen songs about Chinese character, Chinese spirit (noble character, ordinary and outstanding, not afraid of setbacks, active exploration, broad-minded optimism),such as "Plum", "Calm the storm", "Loushiming" and so on; 9songs about national feelings, such as "Mulan Poetry", "True Hero", "Yellow River Yangtze River", "Qingyu Case Yuanxi" and so on; 7 love songs like such as "Mulan Poetry", "Qingyu Case". Magpie Bridge Fairy, Eternal Sorrow Song, Altair Star, Liang Zhu, and so on; songs 5 songs about homesickness, such as "Laisu Homesickness", "Quiet Night Thinking", "Tianjingsha Autumn Thinking", "The End of the World at this time", "Hope for a long time"; songs about landscape, countryside and harmonious symbiosis, such as "Mountain Hawthorn", "Mengxi Lake", "Chile" Song, Xiangzi Trees Around the Village, Fish and Lotus Leaves; 4 songs about children's enlightenment like "Three Characters Classic", "Enlightenment of Vocal Rhythm", "Yong Goose" and "Song of the New School"; 3 songs about treasuring time 3: Song of Tomorrow, "Time and tide wait for no one" and "Golden Clothes"; 3 songs about Chinese and foreign diplomacy like "Climbing Guanquelou" "Song of Living world", "Guan Yong" ; 2 songs about friendshipfarewell 2: "Farewell", "Sigh of farewell to my friend "; 2 popular deduction saluting classics :'Rolling Yangtze River East Passing Water", "Eyebrow Wagging". The selected poems are mostly classical poems with universal emotions, which contain and convey the ideas and values of Chinese traditional culture, and have a strong sense of contemporary real life, can fit the spirit of the times, disseminate the wisdom of ancient sages and philosophy of life, bring people a continuous spiritual support, more convenient for the audience. It helps the audiences combine with their own experience and emotion to complete the recognition and interpretation of the classics.

\section{B. Narrative Expression is Keeping Pace with the Times}

Simple topic selection is not strong enough to support the program's strong content, so the program group also made big effort in the narrative expression.

The first is the presentation of scenes, which is more in line with the visual experience of contemporary audiences. Scene is a major component of TV variety show, perfect scene should have a strong sense of substitution, so that the audience immersed in it, to achieve a pleasant variety of experience. The stage of Everlasting Classics can be divided into two parts according to the singing needs. It can be raised or lowered. The blue dome in the middle of the stage symbolizes the vast traditional culture. The stars light up the stars that echo the heart-shaped devices worn by the audience as well as the classical poetry. Slowly falling bamboo LED screen shows the content of poetry, but the antique and ancient rhyme is full of technological sense. The background screen and the content of the poems are synchronized. The whole stage effect and the poetic mood are perfectly blended and echoed, bringing the audience visual enjoyment of beauty. And the joining of technological elements, such as "Song of Tomorrow" Swaying with the Melody of Artificial Intelligence, "Hope for a Long Time" in the creation of virtual images of Luo Tianyi, make the audience refreshing.

Secondly, it is the construction of emotional community. The classical poetry is the expression of ancient people's feelings and interests, the condensation of life and social state. Although the times change, the cultural emotion expressed by the classical poetry can go through time and space, awakening the common life experience and cultural memory. The superficiality of the inheritance is reflected in the similarity of the author's own experience and story with the classical singer and the related guests, and it is deeply reflected in the mutual reflection and contrast of the spirit and artistic conception they want to express. They may have similar ups and downs in their lives. After Huang Qishan experience her difficulty career life, she can feel the open-minded optimism in Su Shi's "Ding Feng Bo",Luo Jiaying and Wang Mingquan's "Magpie Bridge Fairy" sung out their trusts and understanding of love for 21 years together, and Liang Jun', the volunteer teacher is full of selfconfidence and arrogance in inspiring young people in the mountain with "Moss Flowers". Or the mood and artistic conception, such as Yu Dezhong's nostalgia and nostalgic creation of the "Lai Su Homesickness", Peter Chen praised today's prosperous China with Xin Qiji's dream of the national mirror "Qingyu Case New Year's Eve", anti-cancer woman peasant Bai Ruyun stimulated their own strong optimistic laughter on life by interpretation of Liu Yuxi's "Mood of the Bad Chamber." Or the singers and the classics has the same geographical location and event-similarities. Cao Xuanbin sung "Farewell to the emperor " in Shaanxi dialect told the emotions of friends in Xianyang, Shaanxi Province; "Mulan Poetry" by 
Shang Wenjie, Jiang Muxin and the women's police officers' Choir of the Ministry of Public Security shows the images of women who can't keep their eyebrows and guard their country. The Everlasting Classics, through the combination of poems, songs and people, allows the cultural and spiritual forces behind the poems to infiltrate the hearts of the people of the times and to condense social consensus, thus arousing emotional resonance and building an emotional community.

\section{The Singing Style of the Singers is Keeping Pace with the Times}

The selection of singing guests seems unintentional, but in fact, it is carefully designed to cater to the times, ranging from being a pop star to singing circle, film and television stars, from ordinary and real vegetarians to renowned masters, or using fan effect and fan economy, or waking up nostalgia, or satisfying curiosity psychology, or arousing emotional resonance. But for the old words and phrases new tune itself is a great degree of content innovation. The new melodies and songs fully respect the discourse system and aesthetic, audiovisual habits of the current young people, with more current characteristics to describe the classic, spread the classic.

\section{SHARING AND COMMON TRANSMISSION OF THE INHERITANCE AND DEVELOPMENT}

Tong Tong, general manager and editor of CCTV Creative Media Co., Ltd. said frankly: "The program is not to show and appreciate antiques, but to make classics come alive and popular through the creation of modern people." [1]

\section{A. The Establishment of Sharing Mechanism}

Here, the ancient can be used today. Many songs appeared in the interpretation of the quintessence of Peking Opera and opera elements, like the famous musician $\mathrm{Mr}$. Hu Defu's combined "Laisu Homesickness" with the elements of Taiwan's ancient ballads to express the burning of nostalgia. Here, the foreign can be used in China. Qiu Haiping and Foreign Student Group of Hebei Normal University deduced the "Guan Yong" to absorb the melody of the Indian folk song "Ouch Mom," with the form of songs to promote Chinese traditional culture overseas, so that the form of singing is more lively, dynamic, innovative. Likewise, Li Shutong's "Farewell" is a Chinese classical poetry sung with foreign tunes. This song was born in the early twentieth century in the school music era of the classic, using the tune of the American song "Dreamer and Mother", combining transplanted foreign melody and Chinese poetry to achieve cultural exchanges between the East and the West, realize the integration of fine works. The new sound is ingenious for both today and yesterday. It is a combination of the ancient and the modern, the oriental and the west, the various elements, which is commonly shared and inherited. The sharing mechanism endows the cultural classics with new epochal attributes and influences them on a more realistic level. In a new era, the classics will be renewed.

\section{B. The Realization of the Common Transmission Effect}

"Everlasting Classics" set up a "1+4" media interactive transmission matrix, 1 refers to the television screen program, while supporting each song with 4 different new media products: H5 interaction, Wechat public account, program short video, song audio [2], and according to different terminal characteristics and publicity channels, matching distribution different product content: Short videos produced by mobile, video and fragmented dissemination which meet the need of Internet Tims are launched on official media platforms and commercial video websites such as Youku, Tencent and Aiqiyi to maximize the number of web users. For music platform users, complete audios were launched online on Kugou, Kuwo and QQ music to lock music users. Through the H5 interactive participation program "shake", the music can be real-time listened to, disseminated and shared. Wechat, based on social relations, an interactive exchange information platform help to continue to push and match the high program content. "A little poem has been alone for 300 years. Overnight, hundreds of millions of Chinese remember it", "This is China's character." Tan Weiwei used 20 years of precipitation to blossom "Momei Feng Gu","Tang Dynasty singing makes the world intoxicated! Vienna Mozart Children's Vocal Choir sing <Ascending the Stork Tower $>$ in Chinese, English and German" these extremely emotional rendering and inflammatory articles are from the "Everlasting Classics" official Wechat account. This kind of media-integrated interactive communication matrix has opened up all kinds of communication platforms such as TV, network, terminal, Wechat and music, transformed the one-way linear transmission of TV programs into multi-dimensional interactive communication, and connected the large TV screen with numerous personal information terminals (small screens), enabling viewers to actively forward, disseminate, share, and create a dense one. Circulation channels eventually realized the large coverage and possibility of communication.

\section{Guidance of the Idea of Inheritance}

People from generation to generation practise relay and transmission, from the ancient times to the present age, from the old to the young. Lei Jia and Tan Weiwei, who are devoted to the cultural inheritance project of 56 national folk songs, collect and arrange the national tone, develop and inherit the national style music constantly; Ye's family, who sang "Golden Witch Clothes", adhere to the inheritance of Vietnamese opera for five generations; and Hubei folk song farmer's team, who sang "Guanguanjujiu" from 6 to 72 years old, have been teachers and apprentices for generations. From mouth to mouth, Hubei folk songs have been sung so far. In addition, many of the songs in the program are performed by teenagers and children, such as Jia Ziye and Wang Yicheng in "Fish and Lotus Leaves", Wang Hongxiang of Canadian Chinese origin in "Yong Mei", Zhao Jiajingyun in "Shizhisaishang", Wang Hengyi in "Yong E"... Even in the "New School Song" and "On the Stork Tower" and other songs, a large number of children singing of ancient poetry fragments is added. Children's image implies the hope of inheritance, giving the audience a kind of traditional culture successor, life-long inheritance of strength. 


\section{Penetration of Developing Spirit}

The host Sa Beining and the Appreciation Troupe Carnival deliberately stated the continuous development and evolution of each poem from a historical point of view, emphasizing that the Poetry Classics we recognize and accept today are actually innovations of people of different times, "classics have been perfected in the process of spreading" (Kang Zhen said). The "Three Character Scripture" has been expanded by the people and become today's length. In the Song Dynasty edition, $\mathrm{Li}$ Bai's "Jing Ye Si" was "looking at the moon before the bed" and "looking up at the mountain and the moon with the head up". In order to sing better, the Ming Dynasty people made amendments such as "looking up at the moon before the bed" and "looking up at the moon with the head up". Various cases are intended to highlight the trend of cultural development from ancient to modern times, and to reconstruct the theme of popular classics.

\section{CONCLUSION}

Singing poetry and classics is popular in China. "Everlasting classics" has made the traditional culture keep pace with the times, and established an organic connection between the spiritual wealth contained in the traditional culture and the value pursuit of the new era, so that the mainstream classics once again become the vanguard of popular[3] ,and become a famous sound-able card to disseminate the traditional Chinese culture. Above are the positive exploration for the innovative expression of traditional culture in the new era, hoping to provide new ideas and communication strategies for the development of cultural variety shows.

\section{REFERENCES}

[1] Gao Kai. Re-emerged cultural variety shows of CCTV "Everlasting Classics" during Spring Festival [EB/OL]. Beijing: China News Network, (2018-02-13) [2018-07-16]. https://item.btime.com/m_902078fdc643d7e22

[2] CCTV "Everlasting Classics" Proposals on Two Conferences, popular on campus, and won the Magnolia Grand Prize. Why this program became the new benchmark of the 2018 TV program. [EB/OL]. Beijing: the public Wechat Account of the Everlasting Classics,(2018-0616)[2018-07-16]. https://mp.weixin.q.com/s/kLsyIZmakHHSd_jrH4xQ

[3] Sun Yijun, Zhang Guotao. Poetry and Ci Merge New Music Culture from Generation to Generation--An Analysis of the Artistic Innovation Charm of The Everlasting Classics [J]. China Radio and Television Journal, 2018 (4): 114. 